\title{
EVALUATION AND CALIBRATION OF FIXED-WING MULTISENSOR UAV MOBILE MAPPING SYSTEM: IMPROVED RESULTS
}

\author{
K. Bakuła ${ }^{1}$, W. Ostrowski ${ }^{1, *}$, M. Pilarska ${ }^{1}$, M. Szender ${ }^{2}$, Z. Kurczyński ${ }^{1}$ \\ ${ }^{1}$ Warsaw University of Technology, Faculty of Geodesy and Cartography, Department of Photogrammetry, Remote Sensing and \\ Spatial Information Systems, Warsaw, Poland - \\ (krzysztof.bakula, wojciech.ostrowski, magdalena.pilarska, zdzislaw.kurczynski)@pw.edu.pl \\ ${ }^{2}$ MSP Marcin Szender, Warsaw, Poland - marcin.szender@uav.com.pl
}

\section{Commission I, ICWG I/II}

KEY WORDS: UAV, UAS, Multisensor, LiDAR, accuracy, DEM/DTM, photogrammetry

\begin{abstract}
:
Unmanned Aerial Vehicles (UAVs) are willingly used in photogrammetry and remote sensing, especially for image acquisition, and are characterised by high spatial resolution. UAVs can be used for the fast and, if necessary, frequent acquisition of spatial data, especially for small areas. In recent years, new trends in the development of UAVs have emerged, including the integration of various sensors and the application of ultralight laser scanners. Within the described experiment, UAV data, i.e. RGB and NIR imagery, as well as ALS data were obtained over three test areas. For one test area, the flight calibration was performed. 3 strips were oriented perpendicularly to another 3 strips and the flight was performed on two different heights: 120 and $150 \mathrm{~m}$. In order to process the data acquired for the next 3 test areas, the determined calibration parameters were utilised. The oriented images were used to generate RGB and NIR ortophotos, as well as the point cloud using the Dense Image Matching (DIM) algorithm. Height differences between UAV Laser Scanning (ULS) and DIM clouds were calculated for all test areas. Experiment data from Terrestrial Laser Scanning and check points measured with GPS RTK have been used. Finally, an accuracy of less than $10 \mathrm{~cm}$ was achieved for the DTM. The results were improved by eliminating the problem of horizontal accuracy, but its influence is still slightly visible on the vertical accuracy of the data. The experiment proved the quality of data obtained with the ultralight scanner mounted on the platform moving with much more speed, being an alternative to manned flight missions and multi-rotors UAVs.
\end{abstract}

\section{INTRODUCTION}

Unmanned Aerial Vehicles (UAVs) have been recently willingly used for remote sensing data acquisition. There are different unmanned platforms available on the market (e.g. fixed-wing, multirotor). Over the past years, sensors which can be mounted on UAVs have been clearly developed (Aasen et al., 2018). Various cameras can be mounted on UAVs, e.g. RGB, NIR, thermal, multispectral and hyperspectral. Multispectral and hyperspectral UAV imagery is mostly used in vegetation and agriculture (Matese et al., 2017; Adão et al., 2017). Tetuko et al. (2017) proposed a UAV equipped with a circularly polarized synthetic aperture radar. Other sensors are laser scanning systems. In most cases, laser scanners are integrated with optical sensors, e.g. RGB cameras in order to acquire the images and laser data simultaneously. Some examples of commercial LiDAR systems were presented in Pilarska et al. (2016), however the LiDAR systems developed fast in past years.

Multirotor UAVs are limited because of the possible hovering time. The weight of the sensors mounted on the UAV is one of the factors influencing the time for mission. The latest trend in remote sensing is the simultaneous collection of data from different sensors using unmanned platforms, which result in a higher weight of UAVs. Thus, one of the solutions is mounting the sensors on fixed-wing platforms, which may perform longer flights with the same Maximum Take-off Weight (MTOW). However, a fixed wing may also have some disadvantages in terms of flight speed. In Boon et al. (2017), the fixed-wing UAV was compared to the multi-rotor UAV for environmental mapping purposes. The results showed that the exposure time needs to be considered while acquiring images from a fixedwing, e.g. to vegetation and erosion gully representation. This conclusion referring to LiDAR technology can be more complicated but also related to the sensor.

After Petrie (2013) noticed that progress had been made in the developments of airborne laser scanners preparing them to be used on the lightweight ULS (UAV Laser Scanning) platform, the improvement of LiDAR sensors caused a rapid increase in the application of UAV systems that can be applied in earth science. Increasing the accuracy of LiDAR sensors meant that the integrated measurement systems must be considered with improved algorithms of data processing in order to achieve maximum accuracy possibilities for engineering applications (Crammer et al., 2018). Salach et al. (2018) demonstrated that in the case of UAV-based photogrammetry with dense image matching (DIM) algorithms and ULS accuracy, these data sources can be comparable in uncovered areas and LiDAR is more accurate system for areas covered with medium vegetation. This conclusion is obvious for the remote sensing data collected with manned platforms for forested areas for decades, but it was proved for current sensors for UAVs. This advantage is also confirmed by Wallace et al. (2014). Nevertheless, the development trend of multi-rotors with LiDAR scanners gave a significant increase in the density of point clouds and their accuracy. The necessary efficiency for large-scale analyses proves to be still needed. Light scanners began to appear on fixed-wing platforms (Khan et al., 2017; Bakuła et al., 2018a), where the efficiency of works (flight missions over forests, critical infrastructures) is crucial.

In this article, improved results obtained from a multisensorial mobile mapping system are presented. The article shows the achievable accuracy of the LiDAR system mounted on an 
unmanned platform moving at a high speed and collecting the data over a linear object. The first results of the data acquired from the fixed-wing platform equipped with a LiDAR sensor were presented in Bakuła et al. (2018a). This publication platform was slightly rebuilt in order to obtain higher positional accuracy, which results in higher trajectory accuracy. At the beginning in section 2 of the paper, the platform and data collected in the experiment is presented. Further, in section 3, the methodology is briefly described. In section 4, the results are presented, including a comparison of the ULS to TLS over a calibration area, a comparison between the ULS data to DIM data and terrain measurements for other test areas. Section 5 is a short discussion about the results and provides a summary with conclusions.

\section{UAV PLATFORM AND ACQUIRED DATA}

In this section, the UAV platform was described and the acquired data were presented. Data, which were used within the presented experiment, were acquired within the SAFEDAM project (Bakuła et al., 2018b). The aim of the SAFEDAM project is to create the system for levees monitoring using optical and radar satellite data, aerial imagery, and a non-invasive, unmanned aerial platform, which scans from a low altitude. Within the project, one of the platforms is a UAV - fixed-wing NEO3 equipped with a miniVUX-1 laser scanner, RGB and NIR camera (both Sony Alfa 6000). This platform can be used in the periodical monitoring of levees (in the case of the project - twice a year, during leaf-off season).

\subsection{NEO3 UAV platform}

NEO3 is a fixed-wing UAV, which is equipped with a Riegl miniVUX-1UAV laser scanner, integrated with the GNSS/INS system of Applanix APX-15 UAV. Additionally, on the UAV, two Sony Alfa 6000 cameras are mounted. The first camera collects images in the visible spectrum and the second one in the near-infrared. The NEO was designed by the MSP Company and built within the SAFEDAM project; therefore, the platform is dedicated to the acquisition of multi-source data for levee monitoring. The weight of the UAV is almost $11 \mathrm{~kg}$. Due to the weight and number of sensors on board, the UAV's start is performed with the help of a specially designed rail launcher. In Figure 1, the NEO3 platform with the sensor's location is illustrated.

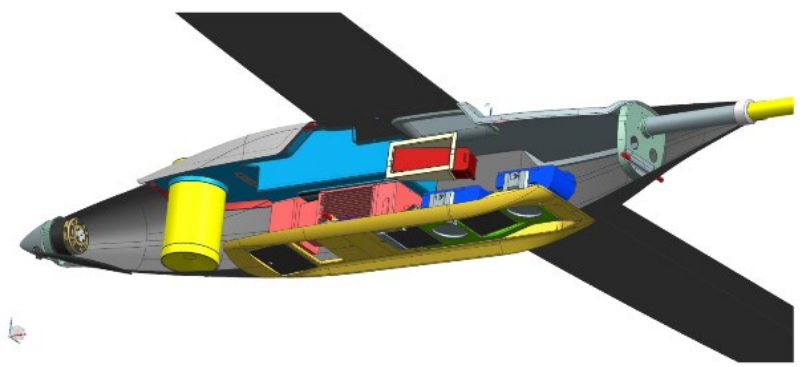

Figure 1. Location of the sensors and components in the platform body, in pink (light red) VUX mini-UAV1 scanner in dark blue two Sony Alpha 6000 cameras (Bakuła et al., 2018a)

\subsection{Collected data}

With the NEO3 platform, ULS and UAV images over three test areas were acquired on October 31 and November 7 and 8, 2018. For every test area ULS as well as RGB and NIR images were acquired. Terrain points were used for the image and ULS data orientation. These points were signalised with chess planes of the size $1 \mathrm{~m} \times 1 \mathrm{~m}$ and measured using RTK technology. The assumed accuracy of the field measurement was $5 \mathrm{~cm}$. The GSD of images was $3 \mathrm{~cm}$.

The test areas consist of a linear part (along dykes) covered with two parallel flights on $120 \mathrm{~m}$ AGL according to the workflow proposed in Bakuła et al. (2016). For the Płock test area (small village Świniary near Płock city) an additional calibration flight was performed, similarly to Bakuła et al. (2018b), where 3 strips were oriented perpendicularly to another 3 strips and the flight was performed on two different heights: 120 and $150 \mathrm{~m}$. The two other test sites were Winiary and Tarnobrzeg. All test site locations are illustrated in Figure 1 which also presents the topography of the area and flight missions. The total length of the levees for the three test areas was approximately $5 \mathrm{~km}$ for Płock, Winiary and Tarnobrzeg.
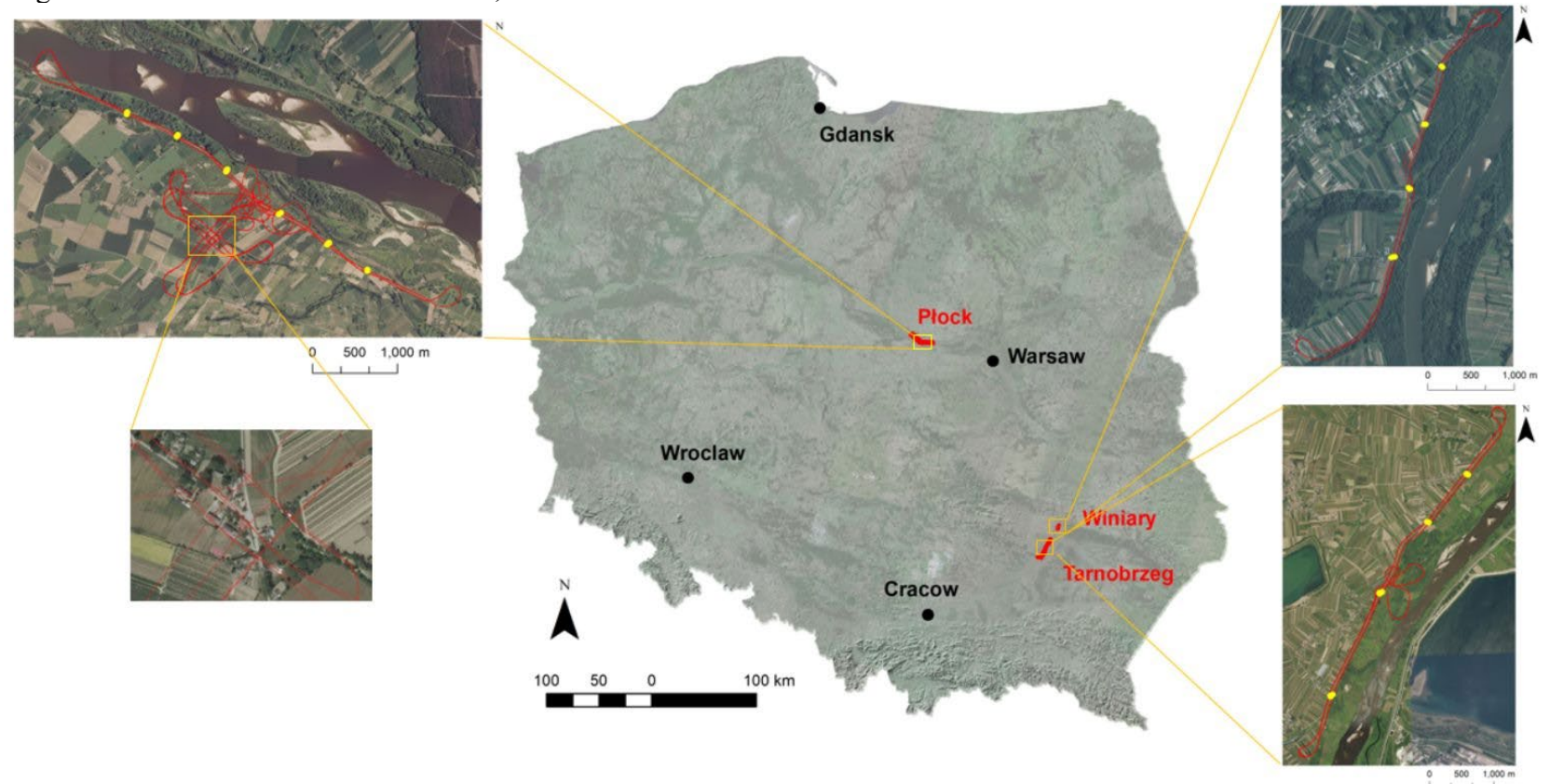

Figure 2. Test sides in the experiment (in red): visualisation of trajectory and control points overlaying the orthophotomap presenting the topography of the test sides 
In the calibration and validation of the results other data have also been used. Terrestrial laser scanning (TLS) point clouds were performed to evaluate the results of the calibration. The crosssection of the levees measured with GPS RTK provided by the Institute of Meteorology and Water Management (performs the terrain measurements every few years in order to monitor the technical condition of the levees) was used to verify the accuracy of the final DTM.

\section{METHODOLOGY}

Regarding the ULS data, the trajectories were processed in POSPac UAV 8.2, with the use of Virtual Reference Station (VRS). During the trajectory postprocessing, for the calibration area (Płock) the lever arms of the scanner were calculated. These values were then applied for the trajectories from the other two test areas (Winiary, Tarnobrzeg). As a next step, the ULS data were oriented in the RiProcess software, which is provided by the scanner producer (Riegl). During orientation, Repression UAV were used; simultaneously, automatic features were used for relative orientation and GCP were used to remove a systematical shift in the vertical direction. The RGB and NIR photos were oriented in Agisoft Photoscan. The image alignment was based on the approximate values of the external orientation parameters of the images acquired during the flights and the control and checkpoints measured in the field. The offsets of both cameras and interior orientation were calculated within the selfcalibration process.

These measurements were compared with the DTM, which was generated from ULS data. In generating the DTM, ULS point clouds were classified in the TerraSolid software. Furthermore, DTM raster files were generated in the ArcMap program where other calculations and visualisations have also been done. Distance calculations and histograms have been done in Cloud Compare.

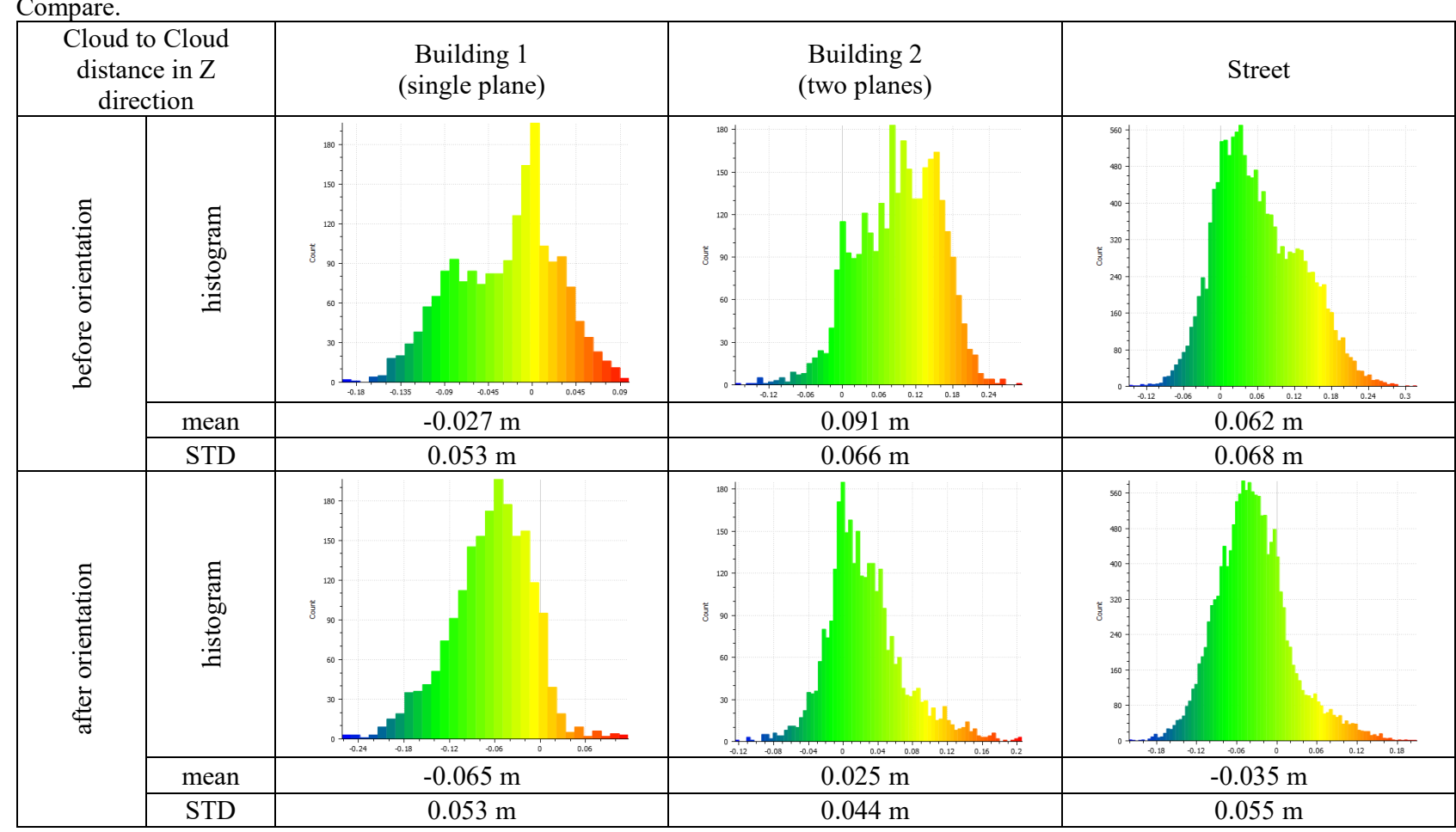

Table 1. Histograms of distances in the Z direction between ULS point clouds and reference TLS point cloud for the Płock test site

\section{RESULTS}

In this section, the results of the ULS and UAV data processing are presented. In the first subsection, the results of ULS data processing were presented. In the second subsection, the results of ULS data processing were presented. In the 4.3 subsection, the processing and the results of the image orientation for two optical sensors were presented. Subsections 4.4 and 4.5 present a comparison between ULS data and a UAV-based DIM point sections.

\subsection{ULS calibration flight}

The lever arm for the calibration area was calculated in POSPac: $\mathrm{x}=-0.420 \mathrm{~m}, \mathrm{y}=-0.020 \mathrm{~m}, \mathrm{z}=0.057 \mathrm{~m}$. These values were applied for all datasets. As it was already mentioned, 3 strips were oriented perpendicularly to another 3 strips and the flight was performed on two different heights: 120 and $150 \mathrm{~m}$.

In ULS data orientation, Z-points were used, which were measured on the road in the centre of the calibration region with the use of RTK technology. The ULS data calibration had two steps, at the beginning, a relative orientation was performed to minimise the differences between the overlapping strips. As a next step, the RTK points were used to orient the point clouds.

The orientation was assessed using TLS data, which were acquired for a part of the test area. The TLS dataset included part of the flat road and the roofs of two houses. Table 1 presents the results of a comparison between ULS and TLS data for the aforementioned road and buildings roofs. cloud and an evaluation of the DTM based on RTK cross-

\footnotetext{
(with local plane modelling with least squares).
} 
It is clearly visible that after the orientation, the mean values are lower, which improves the results obtained on the horizontal surface (street); also the values of the STD are in general smaller and the distribution is more Gaussian. This result might be interpreted as the point clouds from the ULS being shifted downward as a result of orientation and the data from different strips being more consisted with each other. However, the value of the vertical shift (change of mean value) is different for each reference object, and in the case of Building 1, results after orientation are even worse than before.

The differences between the results achieved on the sloped and horizontal planes could be the horizontal (XY) error of the ULS point cloud position. The GCPs used for data orientation in the second step (after the automatic relative orientation based on the detected planes) are horizontal planes on the ground and they cannot be used to verify or improve horizontal positioning. The error of the point cloud horizontal positioning will also influence the vertical displacement between point clouds on sloped roof planes (Tab. 2). In the case of Building 2 where two opposite planes were registered with TLS difference in mean values per plane are visible.

\begin{tabular}{|c|c|c|c|c|c|}
\hline \multirow{2}{*}{ Object } & \multicolumn{3}{|c|}{ Plane } & \multicolumn{2}{c|}{$\mathrm{dZ}[\mathrm{m}]$} \\
\cline { 2 - 6 } & ID & $\begin{array}{c}\text { Direct } \\
\text { ion } \\
\text { (azim } \\
\text { uth) }\end{array}$ & Slope & mean & STD \\
\hline Building 1 & Plane 1 & 160 & 45 & -0.065 & 0.053 \\
\hline Building 2 & Plane 2 & 160 & 30 & 0.001 & 0.034 \\
\cline { 2 - 6 } & Plane 3 & 340 & 30 & 0.044 & 0.040 \\
\hline
\end{tabular}

Table 2. The vertical displacement between ULS and TLS data for single planes in the Płock test site

Because data were acquired from two different flight heights, the results of the evaluation could be disturbed by lower accuracies and densities of strips collected during higher flights. This statement is confirmed by the results added in Table 3 . It can be noticed that for a higher flight altitude, there was a lower density and slightly worse results visible in the STD values were achieved.

\begin{tabular}{|c|c|c|c|}
\hline \multirow{3}{*}{ Test side } & $\begin{array}{c}\text { Statistic } \\
\text { parameter for } \\
\text { orientation error }\end{array}$ & $\begin{array}{c}\text { Before } \\
\text { orientation } \\
{[\mathrm{m}]}\end{array}$ & $\begin{array}{c}\text { After } \\
\text { orientation } \\
{[\mathrm{m}]}\end{array}$ \\
\hline \multirow{3}{*}{ Płock } & mean & 0.073 & 0.004 \\
\cline { 2 - 4 } & median & 0.067 & 0.002 \\
\cline { 2 - 4 } Winiary & STD & 0.037 & 0.004 \\
\cline { 2 - 4 } & mean & 0.416 & 0.002 \\
\cline { 2 - 4 } & median & 0.420 & 0.001 \\
\hline \multirow{3}{*}{ Tarnobrzeg } & STD & 0.023 & 0.001 \\
\cline { 2 - 4 } & mean & 0.234 & 0.004 \\
\cline { 2 - 4 } & median & 0.228 & 0.003 \\
\hline
\end{tabular}

Table 3. The vertical displacement between the ULS and TLS data for single planes in the Płock test site

\subsection{ULS data processing}

Data for the other test areas (levees) were oriented using the signalised points (chessboard). For every area 12 to 18 points were used. Table 4 presents the results of ULS data processing for the control points used in adjustments.

\begin{tabular}{|c|c|c|c|c|c|}
\hline \multicolumn{2}{|c|}{ Flight altitude } & \multirow{2}{*}{\multicolumn{2}{|c|}{$\begin{array}{c}120 \mathrm{~m}(\mathrm{AGL}) \\
4.2-5.2 \\
(\text { mean } 4.6)\end{array}$}} & \multirow{2}{*}{\multicolumn{2}{|c|}{$\begin{array}{c}150 \mathrm{~m}(\mathrm{AGL}) \\
3.0-3.8 \\
(\text { mean } 3.4)\end{array}$}} \\
\hline \multicolumn{2}{|c|}{ Point density (pts $/ \mathrm{m}^{2}$ ) } & & & & \\
\hline \multirow{2}{*}{ Object } & \multirow{2}{*}{ Plane } & \multicolumn{2}{|c|}{$\mathrm{dZ}[\mathrm{m}]$} & \multicolumn{2}{|c|}{$\mathrm{dZ}[\mathrm{m}]$} \\
\hline & & mean & STD & mean & STD \\
\hline $\begin{array}{c}\text { Building } \\
1\end{array}$ & 45 degree & -0.062 & 0.047 & -0.071 & 0.063 \\
\hline \multirow{2}{*}{$\begin{array}{c}\text { Building } \\
2\end{array}$} & 30 degree & 0.003 & 0.023 & -0.002 & 0.045 \\
\hline & 30 degree & 0.029 & 0.026 & 0.063 & 0.046 \\
\hline Street & horizontal & -0.040 & 0.043 & -0.028 & 0.067 \\
\hline
\end{tabular}

Table 4. The results of ULS data processing: statistics from RiProcess before and after orientation

The orientation results showed that before orientation, high residuals were noticed for the control points. For the Winiary area, the residuals were the highest and achieved $0.40 \mathrm{~m}$. For the Płock area, the residuals were the lowest and amounted to approx. $0.07 \mathrm{~m}$. Visualisation of the results of orientation is shown in Figure 3.

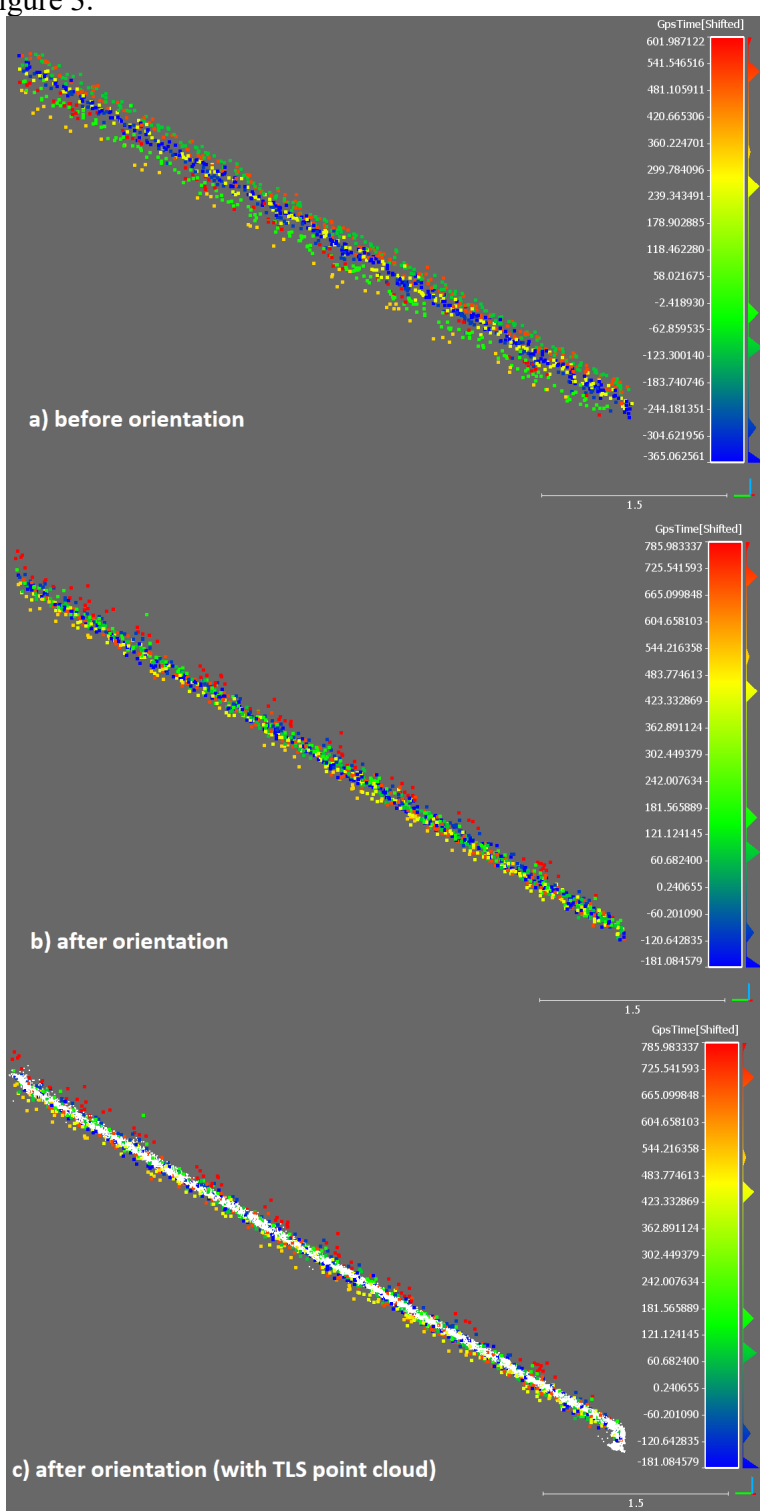

Fig. 3. Visualisation ULS point cloud (coded with GPS time to show strips) before (a) and after (b) with reference TLS data 


\begin{tabular}{|c|c|c|c|c|c|c|}
\hline Test area & Image type & Point type & $\mathrm{mx}[\mathrm{m}]$ & my $[\mathrm{m}]$ & $\mathrm{mz}[\mathrm{m}]$ & $\mathrm{mp}[\mathrm{m}]$ \\
\hline \multirow{4}{*}{ Płock } & \multirow{2}{*}{ RGB } & check & 0.049 & 0.031 & 0.051 & 0.077 \\
\hline & & control & 0.045 & 0.029 & 0.037 & 0.065 \\
\hline & \multirow{2}{*}{ NIR } & check & 0.026 & 0.021 & 0.059 & 0.067 \\
\hline & & control & 0.013 & 0.029 & 0.039 & 0.050 \\
\hline \multirow{4}{*}{ Winiary } & \multirow{2}{*}{ RGB } & check & 0.052 & 0.046 & 0.043 & 0.082 \\
\hline & & control & 0.039 & 0.039 & 0.026 & 0.061 \\
\hline & \multirow{2}{*}{ NIR } & check & 0.028 & 0.030 & 0.053 & 0.067 \\
\hline & & control & 0.042 & 0.032 & 0.032 & 0.063 \\
\hline \multirow{4}{*}{ Tarnobrzeg } & \multirow{2}{*}{ RGB } & check & 0.015 & 0.044 & 0.047 & 0.067 \\
\hline & & control & 0.026 & 0.023 & 0.057 & 0.067 \\
\hline & \multirow{2}{*}{ NIR } & check & 0.012 & 0.036 & 0.047 & 0.060 \\
\hline & & control & 0.032 & 0.021 & 0.022 & 0.044 \\
\hline
\end{tabular}

Table 5. Errors for the checkpoints and control points used for the UAV image orientation

\subsection{UAV data processing}

Photogrammetric data are an important data source in the multisensorial fixed-wing system. They are collected for the production of orthophotos and the raster of vegetation indices. In this experiment, their accuracy is presented in Table 5 where errors of the control and checkpoints points after alignment for all areas are shown to perform also accuracy of source data for DIM. Point clouds from photogrammetric algorithms were used to assess the results of the experiment where TLS data were not available.

Based on Table 5, it can be seen that the position errors of the check and control points range from 0.04 to $0.08 \mathrm{~m}$. This means that the obtained accuracy was within the range of the assumed accuracy $(0.05 \mathrm{~m})$. The errors were smaller than 3 GSD.

\subsection{Comparison of ULS and DIM data}

The ULS data were compared to dense point clouds, which were generated form the RGB images and to the independent RTK measurement of the points on levees. In Table 6, a comparison of the differences between the DIM point clouds and ULS data before and after ULS data orientation is presented. The visualisation of this analysis is presented in Figure 4.

\begin{tabular}{|c|c|c|c|c|c|}
\hline \multirow{2}{*}{ Area } & \multirow{2}{*}{$\begin{array}{c}\text { DIM }- \\
\text { ULS } \\
\text { distance }\end{array}$} & \multicolumn{2}{|c|}{$\begin{array}{c}\text { Before } \\
\text { orientation [m] }\end{array}$} & \multicolumn{2}{c|}{$\begin{array}{c}\text { After } \\
\text { orientation [m] }\end{array}$} \\
\cline { 3 - 6 } & mean & STD & mean & STD \\
\hline Winiary & $\begin{array}{c}\text { Total } \\
\text { distance }\end{array}$ & 0.358 & 0.109 & 0.108 & 0.050 \\
\cline { 2 - 6 } & $\mathrm{dZ}$ & -0.353 & 0.109 & 0.046 & 0.105 \\
\hline Tarnobrzeg & $\begin{array}{c}\text { Total } \\
\text { distance }\end{array}$ & 0.295 & 0.081 & 0.066 & 0.050 \\
\cline { 2 - 6 } & $\mathrm{dZ}$ & 0.291 & 0.083 & -0.047 & 0.066 \\
\hline
\end{tabular}

Table 6. Distances between DIM and ULS point clouds on plane areas before and after orientation

According to Table 6, it can be noticed that after the ULS data orientation, the differences to the DIM point clouds decrease noticeably, from $0.35 \mathrm{~m}$ to $0.05-0.10 \mathrm{~m}$, depending on the area. To show the final results of the orientation, ULS and DIM datasets were compared for areas of asphalt road $\left(9461 \mathrm{~m}^{2}\right.$ for Tarnobrzeg and $2019 \mathrm{~m}^{2}$ for Winiary) which was shown in Table 7. The results indicate that there is a systematic shift that can be caused by the orientation of linear objects or by horizontal error

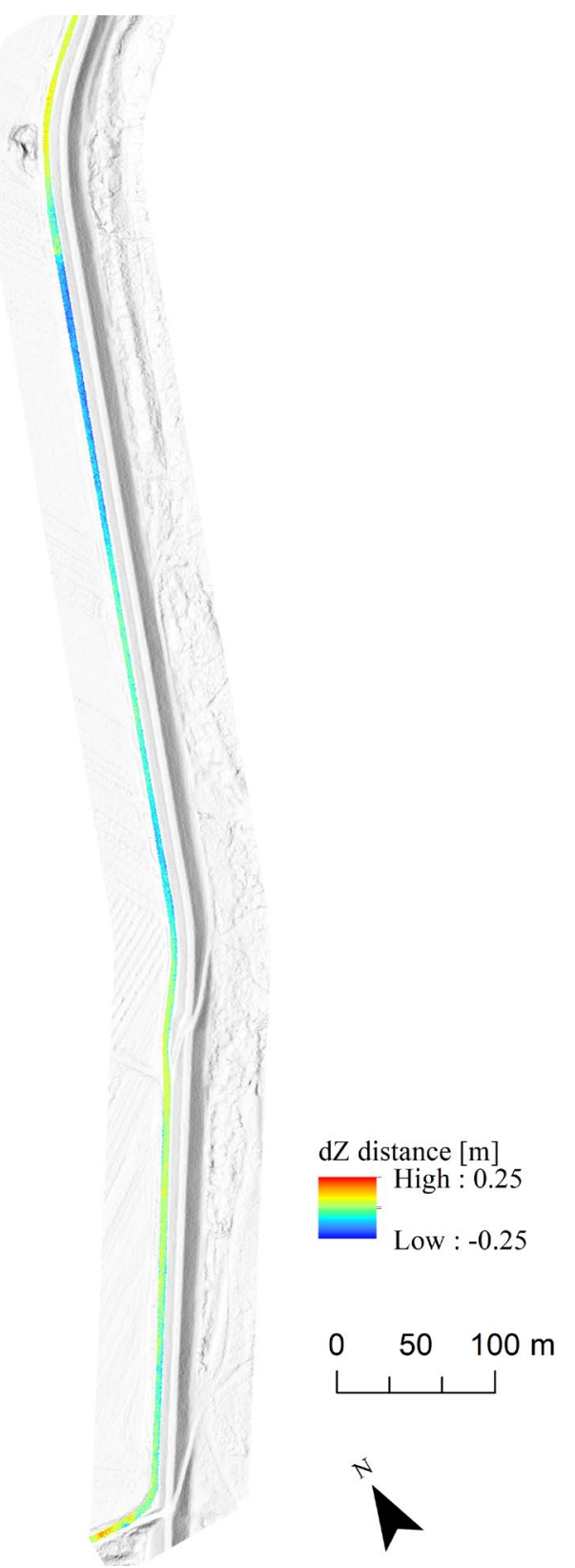

Fig. 4. Visualisation of height differences between the oriented ULS and DIM point clouds overlaying the hillshade model of Tarnobrzeg test sites. 


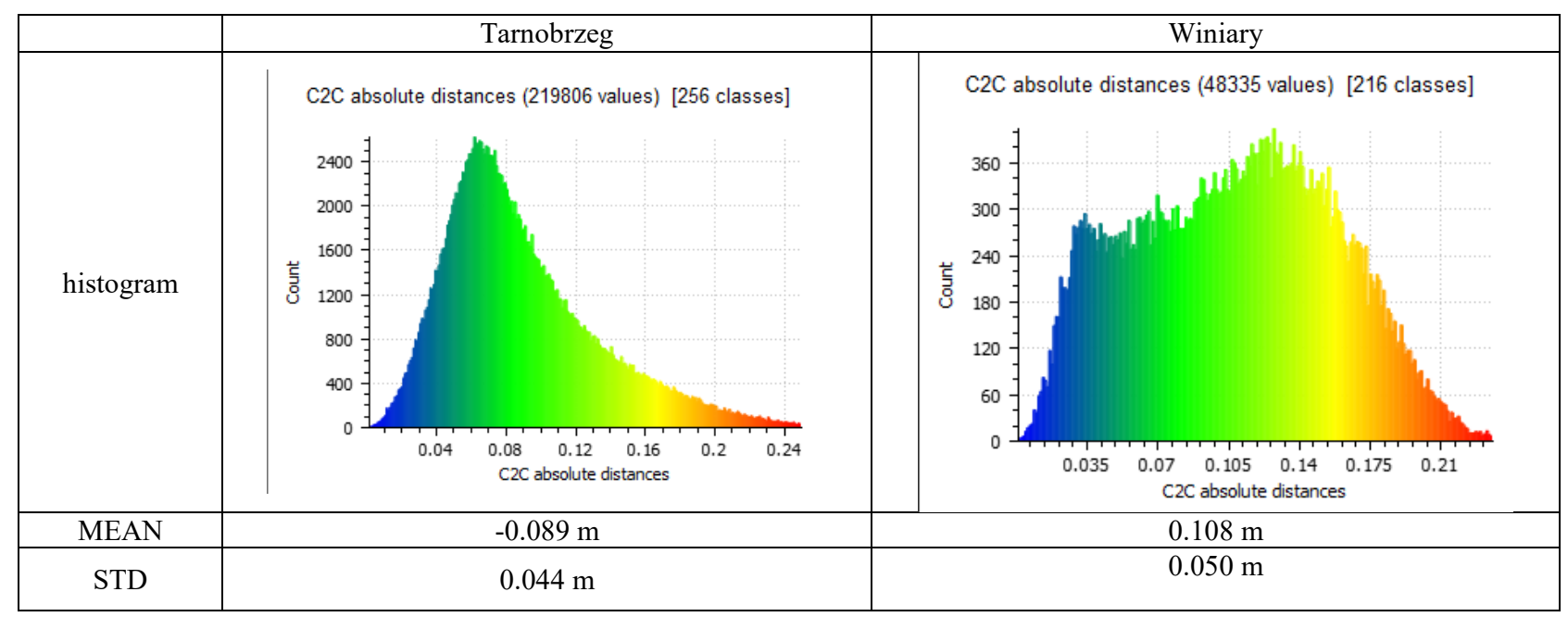

Table 7. ULS-DIM differences for a flat area (asphalt road near levee)

\subsection{Comparison of DTM and terrain measurements}

For the final assessment of ULS data, a comparison with the cross and transversal section for the levee measured with RTK has been made. These measurements were compared with the DTM, which was generated from ULS data (Fig. 5). Heights from the DTM were assigned for every point from the terrain measurement as an additional attribute, and additionally the heights from the RTK measurements and DTM were subtracted. The results were presented in Table 8 .

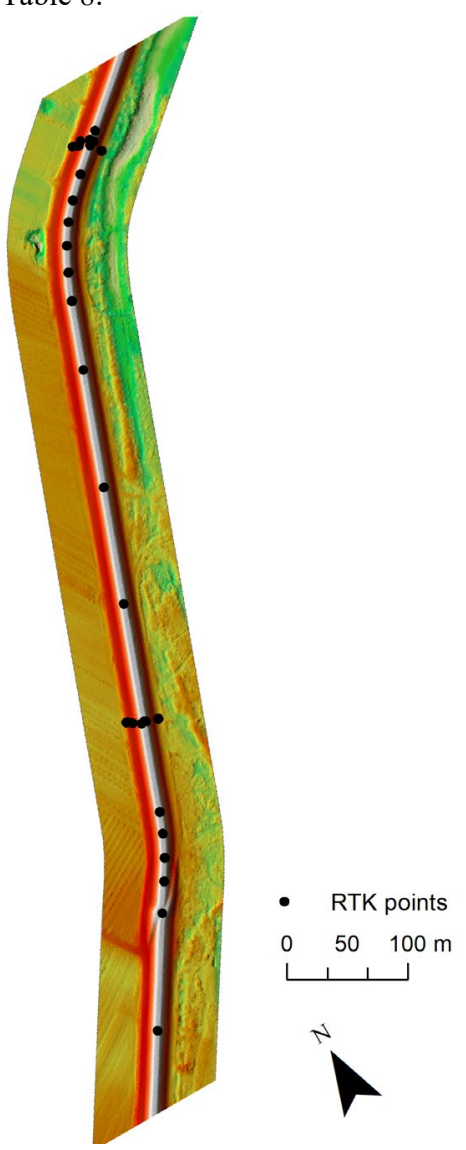

Fig. 5. The example of distribution for cross-section with unsignalised check points overlaying with color-coded digital terrain model

\begin{tabular}{|c|c|c|c|}
\hline & Płock & Tarnobrzeg & Winiary \\
\hline $\begin{array}{c}\text { Number of } \\
\text { points }\end{array}$ & 153 & 243 & 110 \\
\hline $\min [\mathrm{m}]$ & -0.186 & -0.199 & -0.178 \\
\hline $\max [\mathrm{m}]$ & 0.303 & 0.301 & 0.467 \\
\hline $\operatorname{mean}[\mathrm{m}]$ & -0.027 & -0.004 & 0.098 \\
\hline median [m] & -0.034 & -0.015 & 0.060 \\
\hline STD [m] & 0.066 & 0.076 & 0.156 \\
\hline
\end{tabular}

Table 8. Assessment of DTM from ULS data based on the GPS RTK points in the levee sections

Table 8 proved that the final accuracy of the ULS point cloud processed to DTM makes it possible to achieve an accuracy value close to 0.10 metres. The only test site with worse results was Winiary. The difference between the mean and median value means that in the reference data, there must be some systematic error or outliers caused by long distance to VRS and distribution of control points.

\section{DISCUSSION AND CONCLUSION}

The presented results of ULS data and photogrammetric data are at the level of accuracy adequate to the SAFEDAM project goal, i.e. for monitoring flood levees. In this paper, a large number of analyses for three test sites have been conducted, however the analyses performed using the TLS and GPS RTK data do not exhaust the complex topic of series alignment analysis and scanning block orientation.

While the multisensorial platform was still in its preliminary stages, the results presented in Bakuła et al. (2018b) were quite satisfying only for scanning strips without the problem of trajectory accuracy in the that work. In current research, the problem of trajectory accuracy was not noticed. All results were promising and much more accurate.

TLS data with a centimetre accuracy proved that the orientation of the ULS scans improved the result analysed on the roof planes and the horizontal street plane. The point clouds from the DIM made it possible to verify the ULS data in areas for which TLS data was not available. This analysis did not show errors greater than $10 \mathrm{~cm}$. This accuracy for two areas was also confirmed by 
the analysis on the RTK GPS intersections. For the Winiary area, slightly worse results were obtained, showing some undervalued results in this analysis, which can be proved by the systematic error or outliers in the reference data. In general, analysing the accuracy of the resulting DTM generated from data collected with an unmanned fixed-wing system equipped with a laser scanner, reaching the results below $10-15 \mathrm{~cm}$ in accuracy is not difficult. This level is similar to the results obtained in the works in which LIDAR was applied to the multirotor (Bakuła et al., 2016; Salach et al. 2018).

Improving the achievable accuracy, we strive for the precision of registering LiDAR sensors. The final accuracy can be achieved in comparison to the precision level, which was presented in Brede et al. (2017) or Crammer et al. (2018). Accuracy better than $1 \mathrm{~cm}$ should be obtained within the integration with the DIM. Accuracy with fixed-wing will not be as accurate as that of the multirotor, but the advantage of this platform is primarily high efficiency. The disadvantage is the density of point clouds, which is typical for Airborne Laser Scanning.

In the future, further tests of platforms will be conducted and the relation between ULS accuracy and distribution and the number of control points to ensure avoiding any systematic error of ULS strips. Referring to other works it is worth to test combining LiDAR and photo adjustments, which can increase the potential accuracy of the data referring to fixed-wing platform.

\section{ACKNOWLEDGEMENTS}

This research was financed by the National Centre for Research and Development in Defense, Security Programme within the project 'Advanced technologies in the prevention of flood hazard' (SAFEDAM) [grant number: DOB-BIO7/06/01/2015].

\section{REFERENCES}

Aasen, H., Honkavaara, E., Lucieer, A., Zarco-Tejada, P. 2018. Quantitative remote sensing at ultra-high resolution with uav spectroscopy: A review of sensor technology, measurement procedures, and data correction workflows. Remote Sensing, 10(7), 1091.

Adão, T., Hruška, J., Pádua, L., Bessa, J., Peres, E., Morais, R., Sousa, J., 2017. Hyperspectral imaging: A review on UAV-based sensors, data processing and applications for agriculture and forestry. Remote Sensing, 9(11), 1110.

Bakuła K., Ostrowski Wojciech, Szender M., Plutecki W., Salach A., Górski K. 2016. Possibilities for using Lidar and photogrammetric data obtained with an unmanned aerial vehicle for levee monitoring, The International Archives of the Photogrammetry, Remote Sensing and Spatial Information Sciences, International Society for Photogrammetry and Remote Sensing, XLI-B1, pp. 773-780, DOI:10.5194/isprsarchives-XLIB1-773-2016.

Bakuła K., Ostrowski W., Pilarska M., Szender M., Kurczyński Z., 2018. Evaluation and calibration of fixed-wing UAV mobile mapping system equipped with lidar and optical sensors. The International Archives of the Photogrammetry, Remote Sensing and Spatial Information Sciences, 42(1), 25-32, https://doi.org/10.5194/isprs-archives-XLII-1-25-2018.

Bakuła K., Zelaya Wziątek D., Weintrit B., Jędryka M., Pilarska M., Ryfa T., Kurczyński Z., 2018. Multi-sourced, remote sensing data in levees monitoring: case study of SAFEDAM project. The
International Archives of the Photogrammetry Remote Sensing and Spatial Information Sciences, XLII-3/W4, pp. 101-108, https://doi.org/10.5194/isprs-archives-XLII-3-W4-101-2018.

Boon, M. A., Drijfhout, A. P., \& Tesfamichael, S., 2017. Comparison of a Fixed-Wing and Multi-Rotor Uav for Environmental Mapping Applications: A Case Study. The International Archives of Photogrammetry, Remote Sensing and Spatial Information Sciences, 42, 47-54, https://doi.org/10.5194/isprs-archives-XLII-2-W6-47-201.

Brede, B., Lau, A., Bartholomeus, H., \& Kooistra, L. 2017. Comparing RIEGL RiCOPTER UAV LiDAR derived canopy height and DBH with terrestrial LiDAR. Sensors, 17(10), 2371, https://doi.org/10.3390/s17102371.

Cramer, M., Haala, N., Laupheimer, D., Mandlburger, G., \& Havel, P. (2018). Ultra-high precision UAV-based LiDAR and dense image matching. International Archives of the Photogrammetry, Remote Sensing \& Spatial Information Sciences, XLII-1, 115-120. https://doi.org/10.5194/isprsarchives-XLII-1-115-2018.

Khan, S., Aragão, L., Iriarte, J., 2017. A UAV-lidar system to map Amazonian rainforest and its ancient landscape transformations. International journal of remote sensing, 38(8-10), 2313-2330,

Matese, A., Di Gennaro, S. F., \& Berton, A. (2017). Assessment of a canopy height model (CHM) in a vineyard using UAV-based multispectral imaging. International journal of remote sensing, 38(8-10), 2150-2160.

Petrie, G., 2013. Current developments in airborne laser scanners suitable for use on lightweight UAVs: Progress is being made!. GeoInformatics, 16(8), 16-22.

Pilarska, M., Ostrowski, W., Bakuła, K., Górski, K, and Kurczyński, Z. 2016. The potential of light laser scanners developed for unmanned aerial vehicles - the review and accuracy. The International Archives of the Photogrammetry, Remote Sensing and Spatial Information Sciences, XLII-2/W2: 87-95. doi:10.5194/isprs-archives-XLII-2-W2-87-2016.

Salach, A., Bakuła, K., Pilarska, M., Ostrowski, W., Górski, K., and Kurczyński, Z., 2018. Accuracy assessment of point clouds from LiDAR and dense image matching acquired using the UAV platform for DTM creation. ISPRS International Journal of Geo-Information 7, 342; doi:10.3390/ijgi7090342.

Tetuko SS, J., Koo, V. C., Lim, T. S., Kawai, T., Ebinuma, T., Izumi, Y., Baharuddin, M. Z., Gao, S, Ito, K., 2017. Development of circularly polarized synthetic aperture radar on-board UAV JX-1. International journal of remote sensing, 38(8-10), 27452756.

Wallace, L., Lucieer, A., Watson, C. S., 2014. Evaluating tree detection and segmentation routines on very high resolution UAV LiDAR data. IEEE Transactions on Geoscience and Remote Sensing, 52(12), 7619-7628. 